\title{
Adaptation to Stay-at-Home Situation during COVID-19 Pandemic: A Study on the Faculty Members of the Universities in Bangladesh
}

\author{
Tasnim Jerin*, Hafiz Ashraful Haque \\ Department of Coastal Studies and Disaster Management, University of Barishal, Barishal, Bangladesh \\ Email: ^tasnimjerintusliha@gmail.com
}

How to cite this paper: Jerin, T. and Haque, H.A. (2022) Adaptation to Stay-at-Home Situation during COVID-19 Pandemic: A Study on the Faculty Members of the Universities in Bangladesh. Open Access Library Journal, 9: e8391.

https://doi.org/10.4236/oalib.1108391

Received: January 21, 2022

Accepted: February 13, 2022

Published: February 16, 2022

Copyright $\odot 2022$ by author(s) and Open Access Library Inc.

This work is licensed under the Creative Commons Attribution International License (CC BY 4.0).

http://creativecommons.org/licenses/by/4.0/

\begin{abstract}
This study is concerned with the perceptions and adaptation strategies of the respected university faculty members in Bangladesh regarding the current COVID-19 pandemic. A self-administered survey questionnaire was filled out by 163 faculty members serving in a variety of academic disciplines in Bangladesh, among which 161 responses were considered for this study. This study found that the majority of respondents were staying home in urban areas (85\%) with their families at the time. Almost all the respondents (98\%) kept themselves updated with the facts and news regarding this pandemic with the prime source of information being electronic media and social media. The top three activities performed during the stay-at-home situation were found to be study and research, skill development, and helping out in household chores. The interaction with students was found to be $96 \%$, while more than half of the respondents (57\%) were taking online classes. The respondents reported both positive and negative impacts of the stay-at-home situation, which are further discussed in the paper.
\end{abstract}

\section{Subject Areas \\ Social Sciences and Humanities}

\section{Keywords}

COVID-19, Pandemic, Adaptation, Stay-at-Home Situation, Faculty Member, Bangladesh

\section{Introduction}

The whole world is going through the aggression of a hidden enemy; a highly 
contagious, lethal, pathogenic respiratory viral infection [1] called the coronavirus disease (COVID-19). After the first emergence of the virus in Wuhan, China at the end of 2019, on January 20,2020, it was feared by the Chinese experts to have a major outbreak through human to human transmission [2]. With the increasing number of cases, transmission, severity, and considering the risks of spreading to other countries, WHO declared the COVID-19 as a global emergency on January 30, 2020 addressing the need for coordinated international response to fight against the deadly virus [2] [3]. In the months of February and March, almost all the countries were detected of having confirmed COVID-19 cases [3] and COVID-19 was declared as a pandemic by World Health Organization (WHO) on March 11, 2020 [4] [5]. As of August 31, 2020, it took a total of 844,312 lives and infected over 25,118,689 individuals all over the world after its emergence [6]. Bangladesh is not an exception to experience the horrifying pandemic situation with the total death of 4281 and 312,996 confirmed cases of COVID-19 from its first emergence on March 8, 2020, up to August 31, 2020 [7].

SARS-CoV-2, severe acute respiratory syndrome coronavirus (SARS-CoV), H5N1 influenza A, H1N1 2009, and Middle East respiratory syndrome coronavirus (MERS-CoV) are all members of coronaviruses [1], but with high and unknown transmissibility, severity in mortality and morbidity and biological natures SARS-CoV-2 is found different from SARS-CoV and MERS-CoV [8] [9]. As with unknown pattern of transmission and different biological features of COVID-19 [8] [9], the absence of clinically approved antiviral drug or vaccine [1] has posed a threat to human life and health and made a quite challenging situation for all the countries to prevent it [10].

In the absence of a potential and clinically approved drug or vaccine, during the emergence of a pandemic potential novel influenza a virus, nonpharmaceutical interventions (NPIs) are taken to help slow transmission of the virus in the community [11]. According to the Center for Disease Control and Prevention, NPIs are mitigation actions that people and communities can adapt to slow down the spread of respiratory diseases like pandemic influenza apart from getting vaccinated or taking medicine [12]. As the COVID-19 virus is mainly transmitted through saliva droplets or nose discharges of an infected person, contact, and aerosols [13] [14], NPIs are considered very effective to contain the spread of the virus [15] and suggested to follow until the discovery of the vaccine. NPIs can be taken at all levels from individual to the community which includes, proper handwashing, sneezing etiquette, isolation of sick people, social distancing measures such as the closing of schools, working from home, canceling, and restricting public gatherings, etc. [11] [15]. By reducing the person-to-person transmission, delaying the epidemic peak, buying some time to withstand the crisis, relieving pressure on the healthcare system, these mitigative measures are considered as crucial components of the public health response to influenza pandemics [16]. Studies have shown that social distancing measures such as isolation or quarantine of infected people, school closure, banning of public gatherings, etc. were very much effective in reducing the transmission during the 1918-19 pandemic 
in the US [17] [18]. Also, during SARS, MERS, 2009-10 epidemic, Ebola, social distancing measures were found to be effective [11] [19] [20] [21] [22]. Observing the effectiveness of nonpharmaceutical interventions during outbreaks, the US Centers for Disease Control and Prevention recommends activating them if any virus strain case is confirmed in an area or region [23].

With the coronavirus outbreak, Wuhan at first went to initiate its NPIs with a lockdown on January 23, 2020, with other cities of Hubei province [2]. With the increasing severity and high transmissibility of COVID-19 and absence of a vaccine, almost every country has adopted aggressive nonpharmaceutical interventions like mandatory lockdown, work from home, school closure, social distancing, international travel bans, school closure, etc. to contain the virus [24]. To contain the virus and reduce transmission, Bangladesh also followed NPIs like other countries [24]. Starting with the reduced international flight and border closure, Bangladesh announced on 16 March that all kinds of educational institutions to remain closed from March 17, 2020 [25] and went to a countrywide lockdown from March 26, 2020, declaring a public holiday [26]. WHO (2020) advised people to maintain proper hygiene, handwashing, maintain physical distancing, and mostly to stay at home [27]. Protecting the community from exposure to the virus, people were encouraged to stay at home [8] and billions of people were staying at home as an adaptation measure to fight the COVID-19 [24]. The Prime Minister of Bangladesh Sheikh Hasina urged people to stay at home and obey the protective measures while declaring the public holiday to contain the spreading of the new coronavirus [28].

Staying at home probably sounds very comfortable. But during a pandemic situation, staying at home for a long time may not be comfortable or economically feasible for a poor country. Several studies [15] [29] showed that staying at home is very much effective in containing the virus at some level. All these implications greatly depend on the reaction, perception, and attitude of the community people and vary from community context whether they are finding these measures useful or not [30].

As the concept is very much new to the context of Bangladesh, our study intends to explore how the faculty members of different universities of Bangladesh have adapted to the stay at the home situation during the COVID-19 pandemic.

\section{Methodology}

\subsection{Study Context, Target Group, Sampling and Data Collection}

The study followed a quantitative method. A web-based self-administered survey was conducted to collect the data from the participants. A semi-structured questionnaire was prepared by using the google doc form where both open-ended questions and closed-ended questions were asked. The survey was conducted to analyze the COVID-19 perception and the adaptation strategies to the stay-athome situation that were being carried out by the respected faculty members of different universities in Bangladesh during the COVID-19 pandemic. The ques- 
tionnaire was divided into four sections, e.g., personal information, perception of COVID-19, household characteristics, and general stay-at-home situation. The ethical issues related to the survey were considered to comply with the WHO guidelines on the "monitoring knowledge, risk perceptions, preventive behaviors, and trust to inform COVID-19 pandemic outbreak response" [31]. The faculty members of public and private universities in Bangladesh were approached to participate in the survey via email, explaining the purpose, ethical ground, and the questionnaire link. Data were collected from May 30 to August 30, 2020. A list of total study samples (i.e., 40 universities from which faculty members responded) is presented in Table 1. A total of 163 responses were received, among which 161 responses were considered for this study as the other two responses were incomplete.

Table 1. Total sample universities under the study.

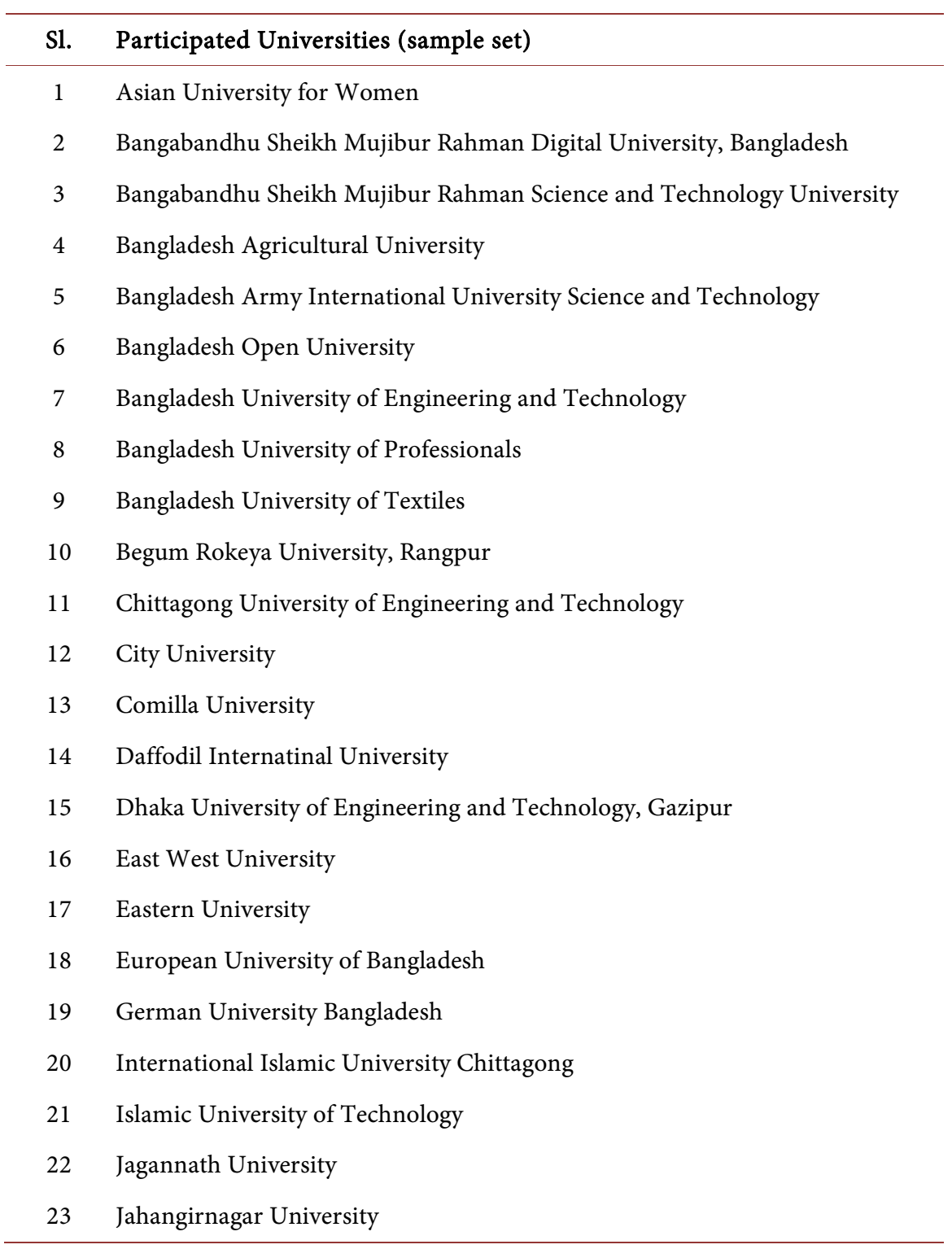




\section{Continued}

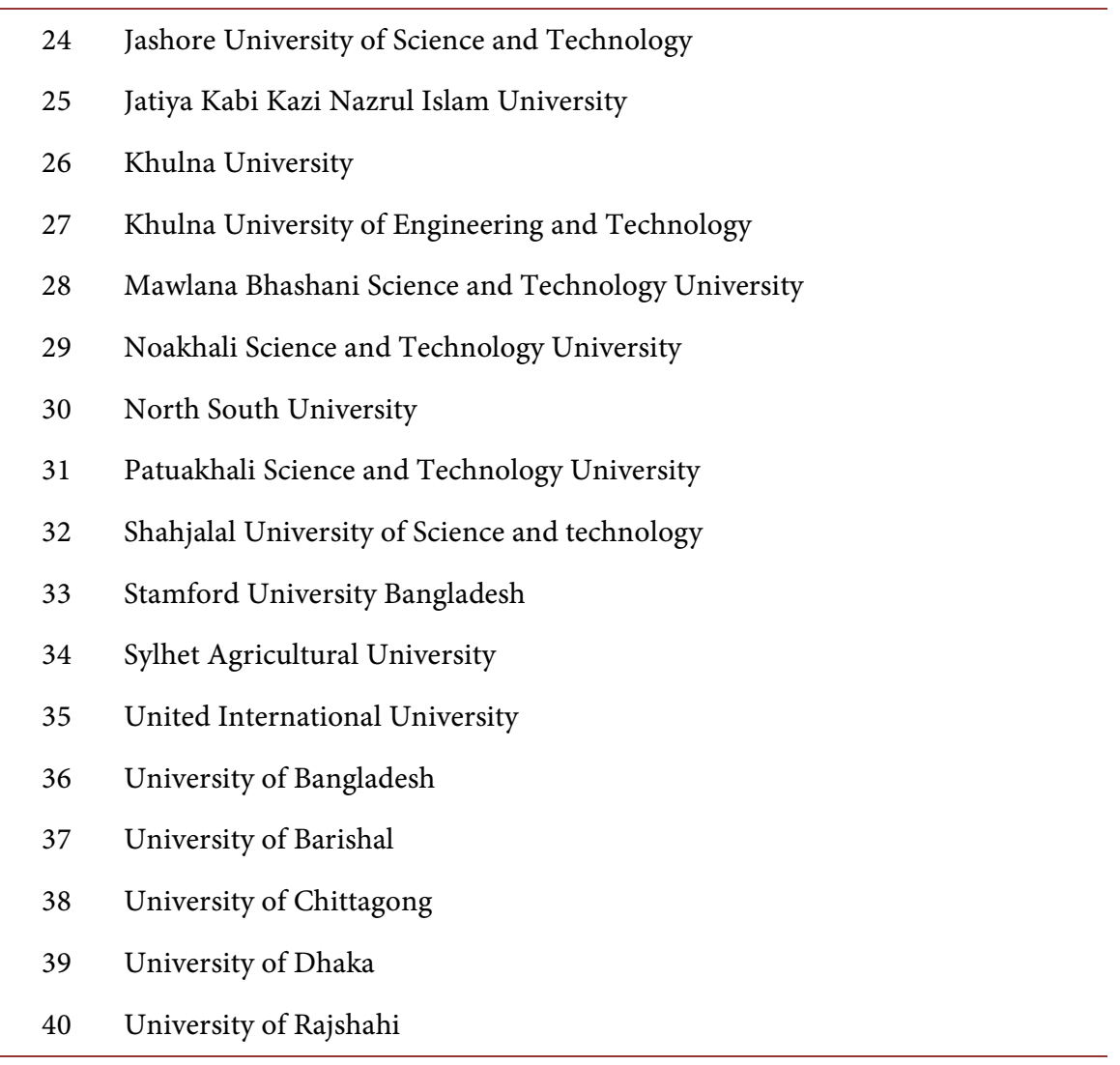

\subsection{Measurement and Analysis}

Apart from the direct graphical representation of the found results in percentages and proportions, the responses with multiple options being recorded from a single respondent for a particular question were explored by cross-tabulation.

\section{Results and Discussion}

\subsection{Demographic Profile of the Respondents}

The demographic profile of the respondents is shown in Figure 1. The survey was dominated by male faculty members. It was realized that about three-fourths of the respondents were male (Figure 1(a)). As per Figure 1(b), the majority of the respondents hold the position of Assistant Professor (42\%) in their respective institutions. Figure 1 (c) shows that about $60 \%$ of the respondents hold up to a master's degree. The stay-at-home condition at the household level and the geographical location of stay are shown in Figure 2. More than half of the respondents are staying home with their spouse and children and the second dominant family structure is comprised of parents and siblings (Figure 2).

\subsection{Perception on COVID-19}

The perception of the respondents on the COVID-19 outbreak and spread was recorded through the survey. From Figure 3(a), the result shows that $51 \%$ of the 


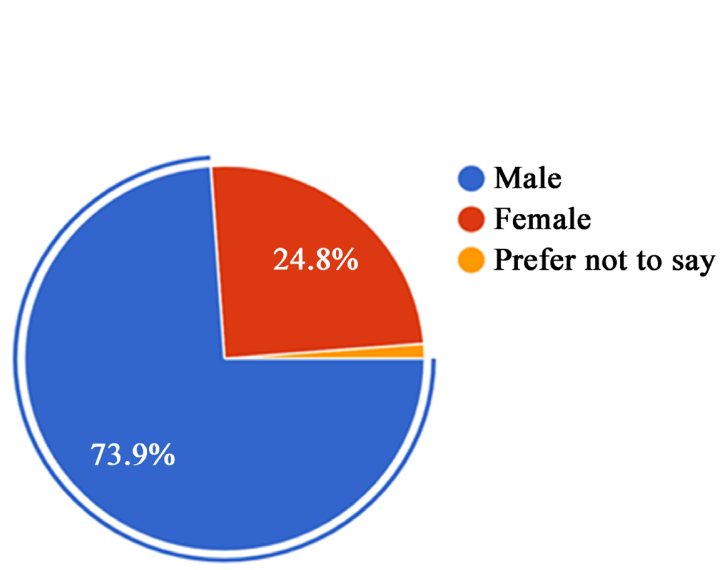

(a)

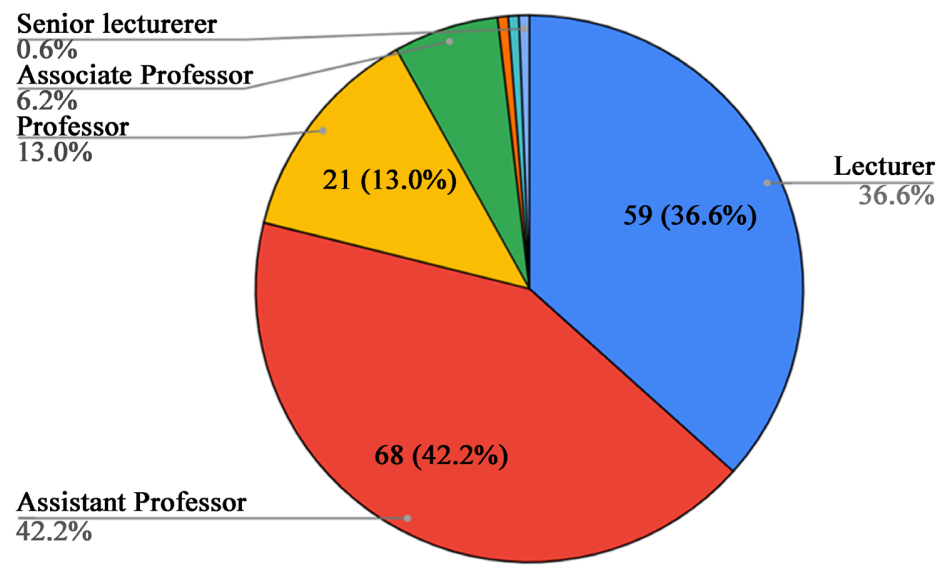

(b)

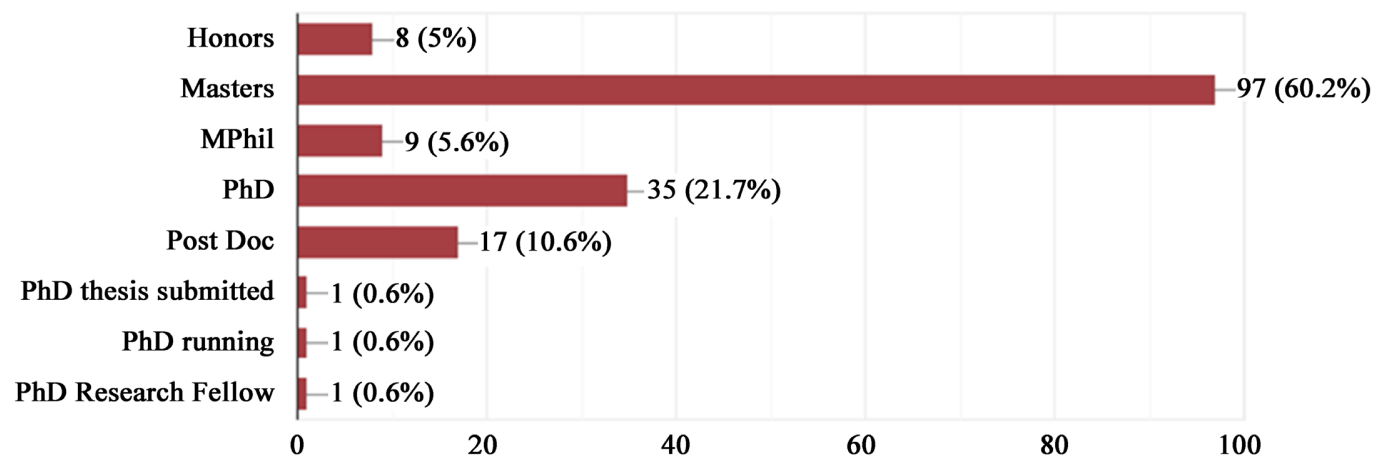

(c)

Figure 1. Demographic profile of the respondents of the survey. (a) Gender; (b) Position in the institution; (c) Educational qualification.

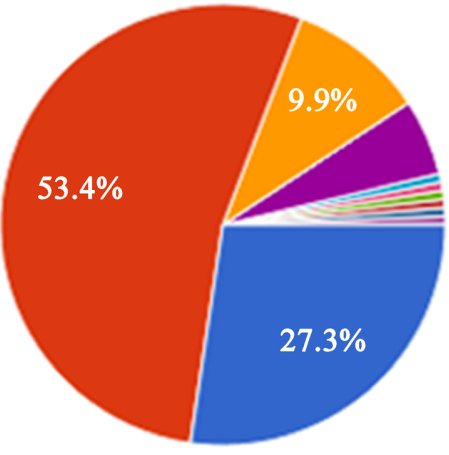

(a)
With family (Father, mother, siblings)

With family (Husbandwife, children)

With joint family

With colleagues/friends

By yourself

Parents, wife

Study leave and so that alone

Father,Mother, Wife, Children

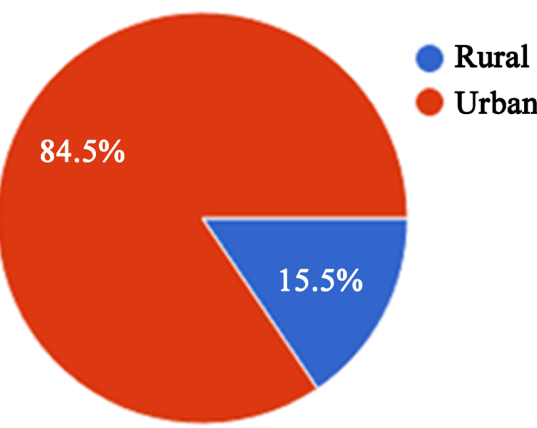

(b)

Figure 2. Household characteristics during stay-at-home. (a) Stay-at-home period: with whom staying; (b) Location of stay.

respondents are informed of the virus through electronic media and the second dominant source of knowledge was social media (41\%). Two-thirds of the respondents were not much familiar with the terms isolation, lockdown, quarantine, physical or social distancing before the pandemic (Figure 3(b)). People with breathing difficulties ( 51\%) and people aged 56 years and above $(\sim 40 \%)$ are at the peak of health risk according to the respondents as shown in Figure 3(c). Figure 3(d) and Figure 3(e) present the prevention and safety perceptions of the respondents on how to prevent or slow down the spread and how to maintain 
the safety of the family. Most of the respondents preferred to stay at home when feeling sick, self-isolation, maintain physical and social distancing, wash hands, take shower, disinfect things as preventive measures. These safety and prevention perceptions are in line with the findings by PAHO (2020) as well as Wang (2020) [15] [29].

\subsection{Adaptation to Stay-at-Home Situation}

The adaptation strategies followed by the respondents show a wide range of variations

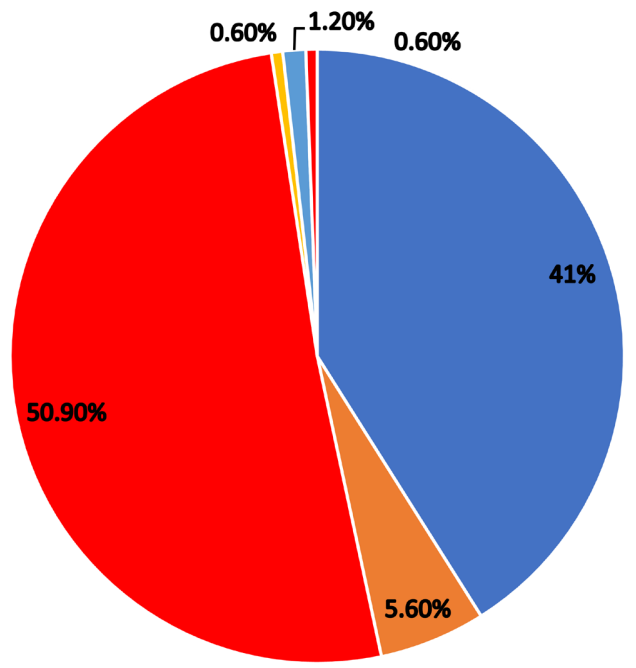

" Social Media (Facebook, Twitter, Instagram, Youtube, Blog, etc.)

- Print media (Magazines, Newspapers, Flyers, Newsletters, etc.)

- Electronic media (Television, Radio, Internet, Fax, etc.)

= One of my student told me about it in the classroom

- Workplace (Peers and Colleagues)

- Research articles

(a)

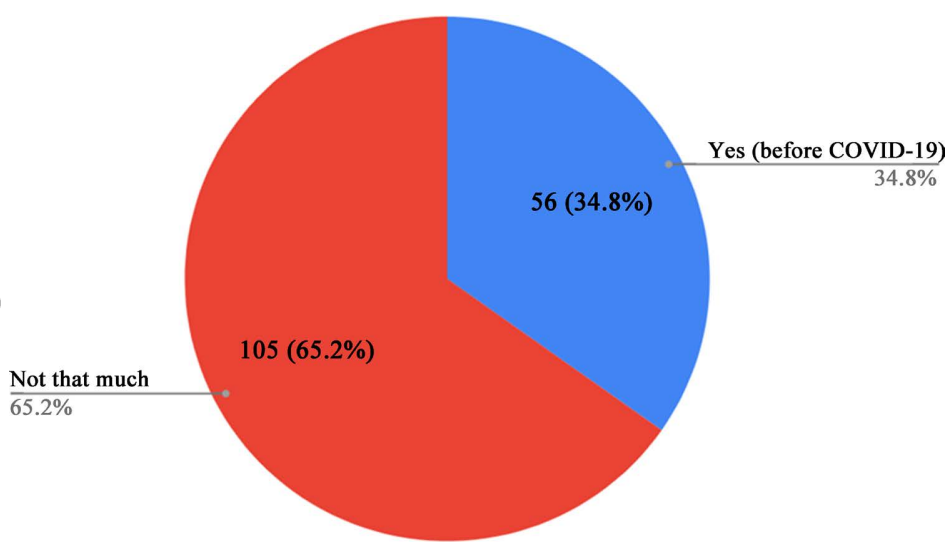

(b)

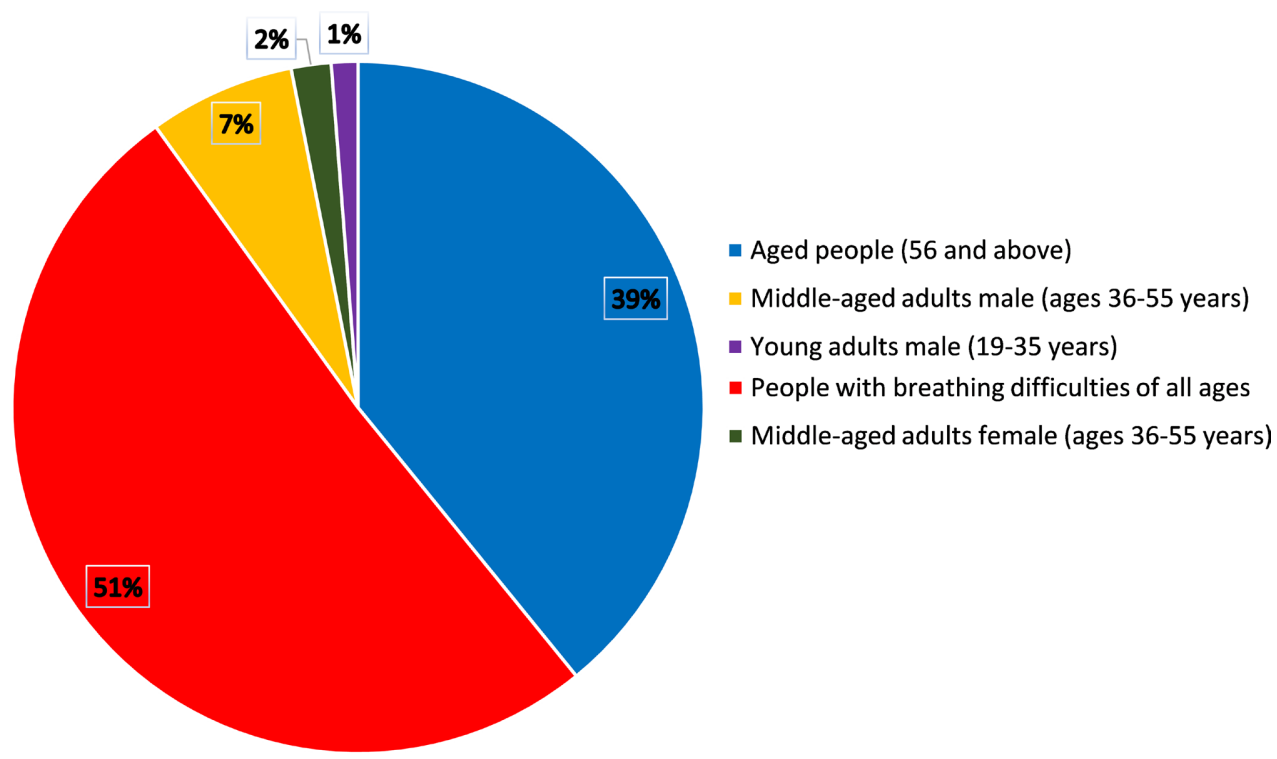

(c) 


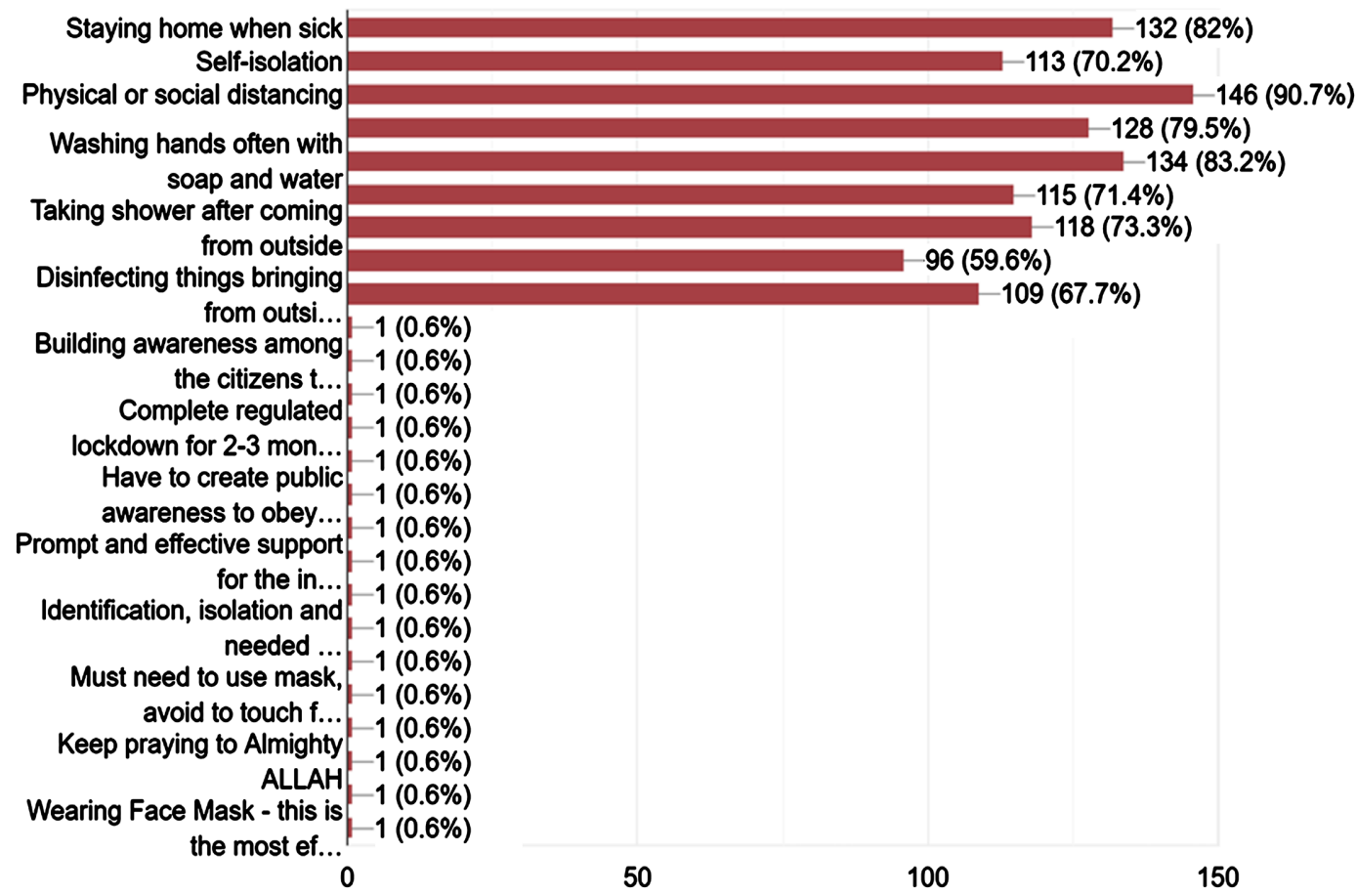

(d)

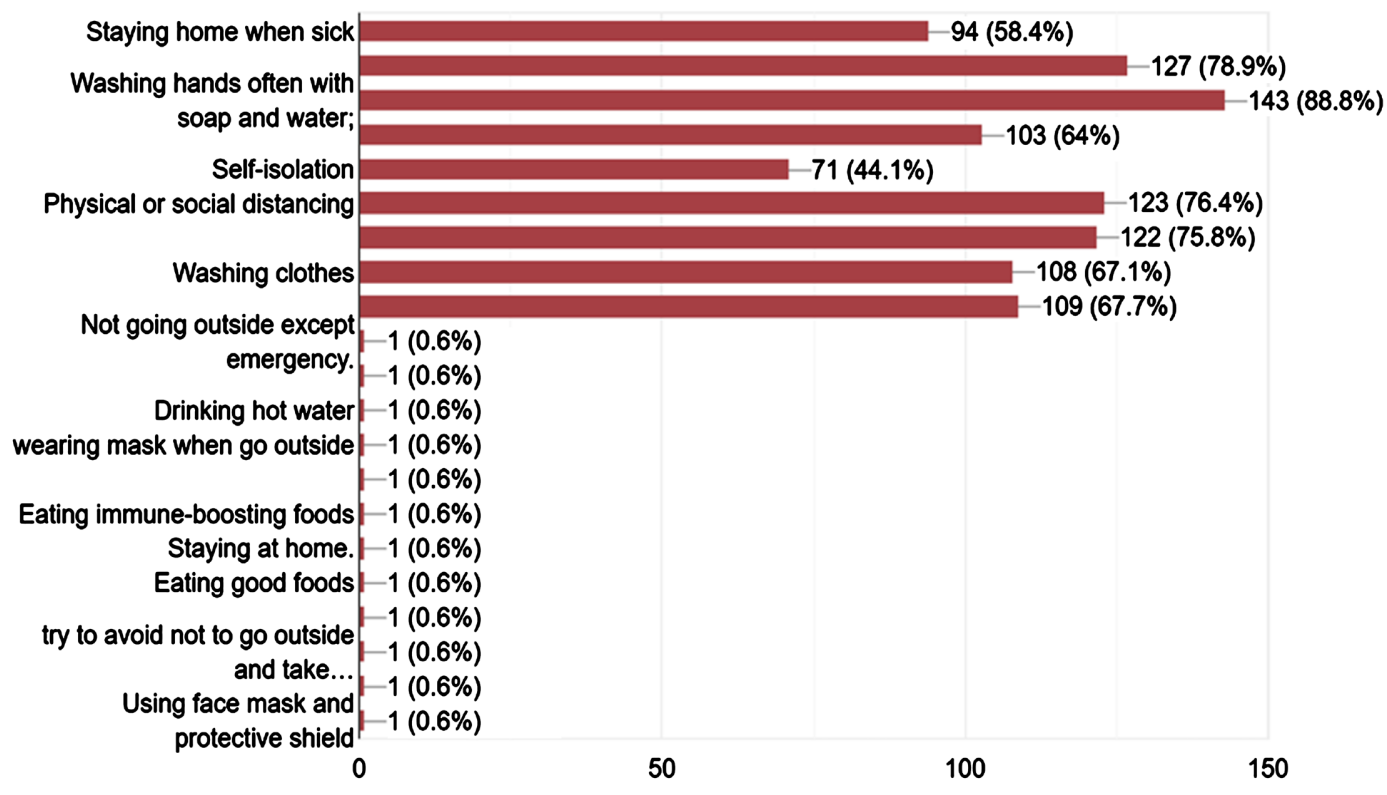

(e)

Figure 3. Perception of the respondents on COVID-19. (a) Knowledge of COVID-19; (b) Familiarity with the terms isolation, lockdown, quarantine, physical or social distancing; (c) Health risk by age group; (d) Prevention or slowing down the spread; (e) Maintaining the safety of the family.

(Figure 4). While $98 \%$ of the respondents keep themselves updated on the COVID-19 news, more than half $(\sim 57 \%)$ have the sole responsibility of going out mostly once a week $(\sim 30 \%)$. Almost $80 \%$ are found to be developing new skills, more than $90 \%$ of the respondents are aware of safe removal of trash daily and most of them are positive ( 43\%) and compelled ( 43\%) to the new lifestyle as 


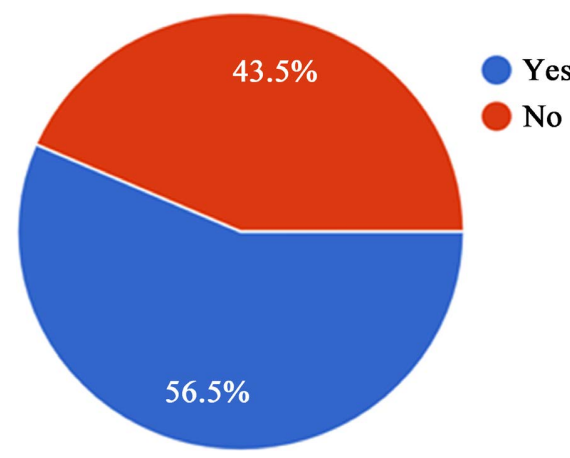

(a)

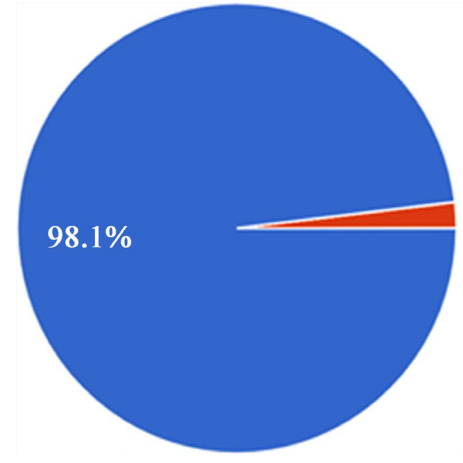

(c)

- Compelled/No other option $=$ Positively

" Negatively " Neutral/No change

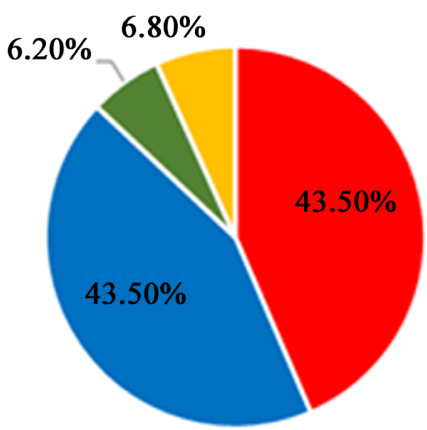

(f)

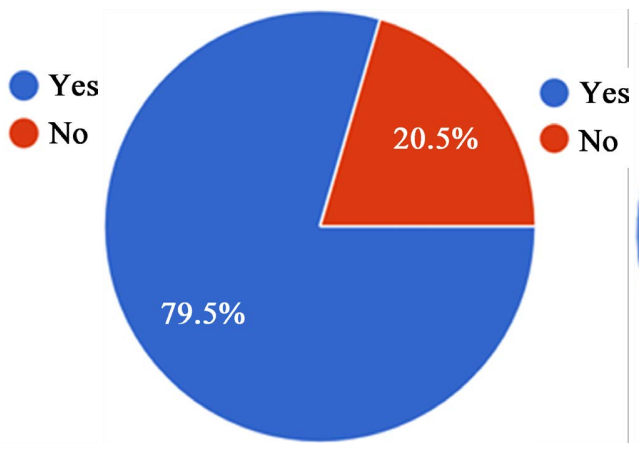

(d)

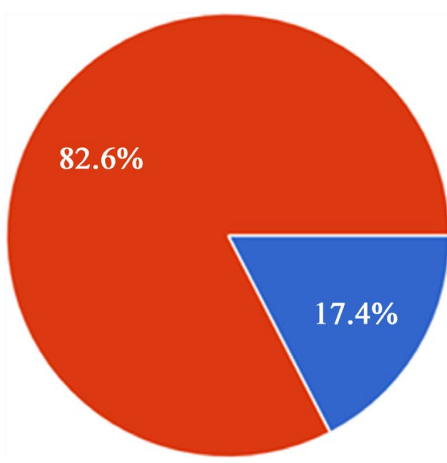

(g)
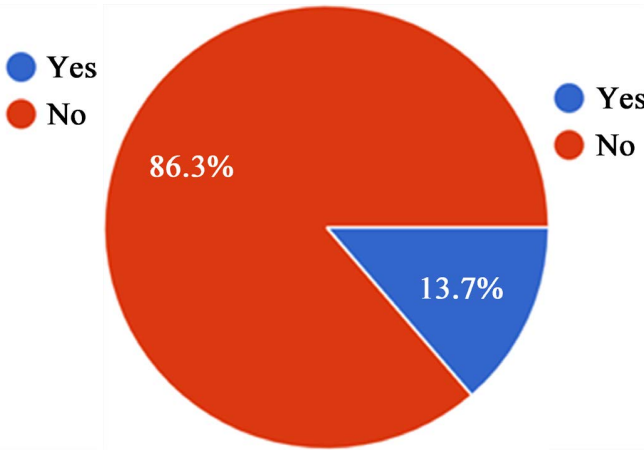

(h)

Figure 4. Adaptation status for stay-at-home condition. (a) The sole responsibility of going outside; (b) How often go out; (c) If keep oneself updated on COVID-19; (d) Whether develop new skills; (e) If trash is removed daily; (f) Feelings about changed lifestyle; ( $\mathrm{g}$ ) If the purpose of staying at home is fulfilled; (h) If the only government is responsible to manage the crisis. 
there are no other options. About $86 \%$ think that it is not the sole responsibility of the government to manage the situation, while about $83 \%$ think that the purpose of staying home is not fulfilled in our case.

The respondents of the study have reported both positive and negative impacts of staying home (Figure 5 and Figure 6). The top positive impacts are spending time with family members, working for self-development and research, helping with household chores, doing pending tasks, and getting some rest after long. The reported negative impacts on top are stress, anxiety, feeling upset, and helplessness. The other adverse impacts are lack of helping hand for household chores as well as lack of socialization. More than one-third of the respondents $(\sim 38 \%)$ reported that they could not go home due to lockdown, home quarantine, and self-isolation.

\subsection{Interaction with Students and Online Class}

As Figure 7 shows $96 \%$ of the respondents are in regular interaction with the students, $57 \%$ of them are taking online classes even if most of them (45\%) are not sure of the effectiveness of the online classes.

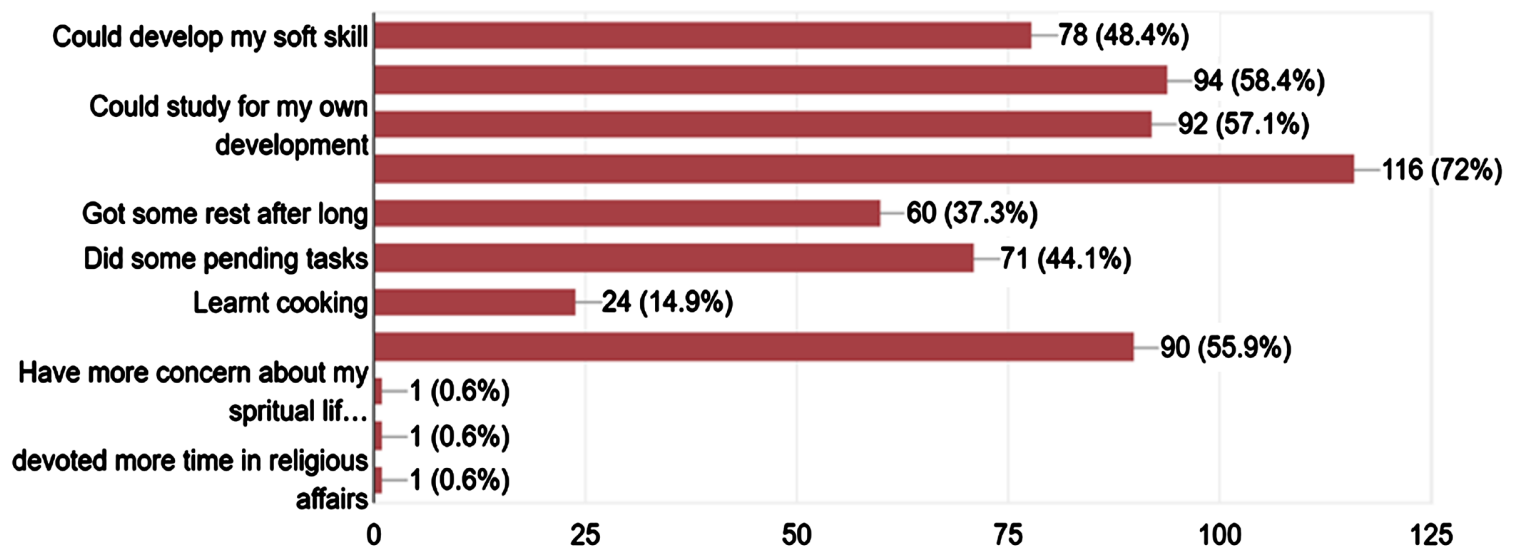

Figure 5. Positive impacts.

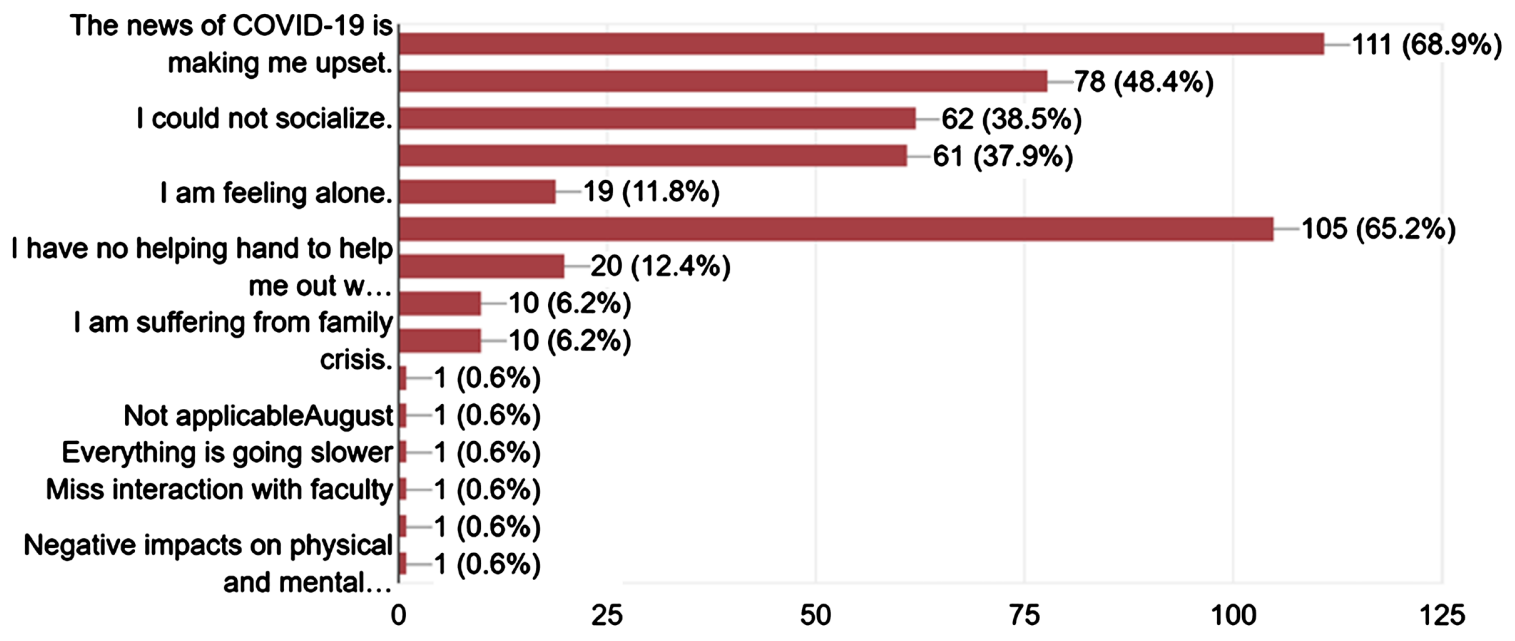

Figure 6. Negative impacts. 


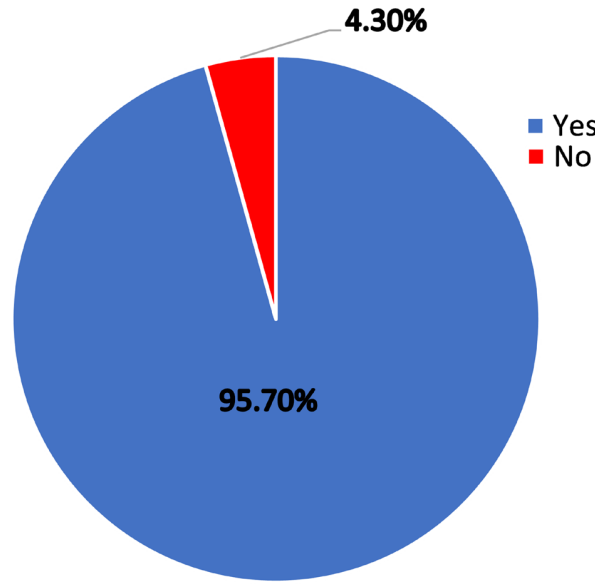

(a)

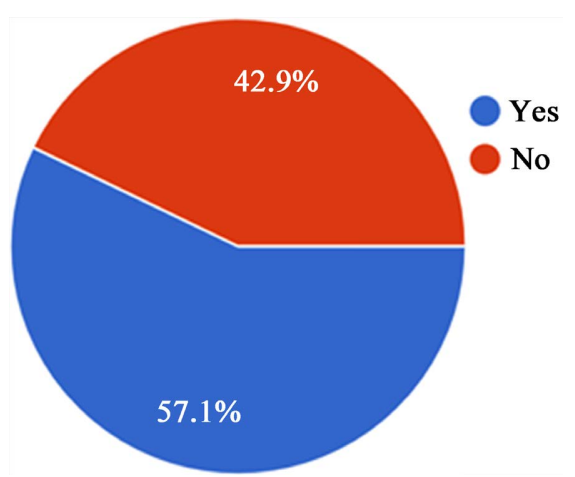

(b)

\section{0}

60

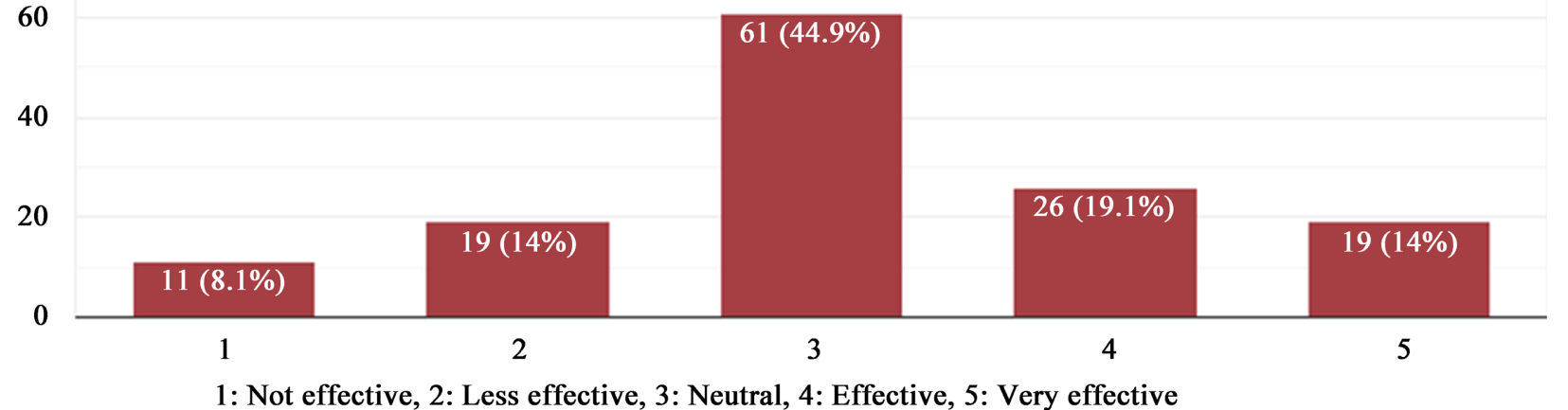

(c)

Figure 7. Interaction and online class with the students. (a) Interaction with the students; (b) Whether taking online class; (c) Effectiveness of online class.

\subsection{Life after COVID-19 Crisis or Life with COVID-19 Crisis}

More than half of the respondents (87) have not commented on this part. Some of the important comments are discussed here. The majority who commented think that life will be more stressful, uncertain, and troublesome after the COVID-19 crisis. Careful preparedness, awareness-raising, systematic management, and monitoring, as well as priority in the health sector in the government policy, are emphasized by the respondents. About $10 \%$ of the respondents who commented pointed out the weakness in government policies and strategies regarding COVID-19 management. A positive attitude towards the new normal, youth leadership besides government activities and extended use of technology in health, education, and economy is appreciated by some of the respondents.

\section{Conclusion}

The study revealed a structured pattern of adaptation strategies and consequences through the responses being involved. As the respondents belong to academia, the reflection of their actions and opinions are influential for others, the positiv- 
ity towards the new normal situation in particular. Considering the intensity of this global pandemic, every single human being should be aware of it, taking the safety measures and hygiene practices guideline by the WHO as long as a permanent solution in the form of the effective vaccine comes out. Until then reducing the exposure by staying home and working from home have to be prolonged under these circumstances.

\section{Acknowledgments}

The authors would like to thank the respondents of the questionnaire survey, without whom this study would not have been possible.

\section{Conflicts of Interest}

The authors declare no conflicts of interest.

\section{References}

[1] Shereen, M.A., Khan, S., Kazmi, A., Bashir, N. and Siddique, R. (2020) COVID-19 Infection: Origin, Transmission, and Characteristics of Human Coronaviruses. Journal of Advanced Research, 24, 91-98. https://doi.org/10.1016/j.jare.2020.03.005

[2] Aljazeera (2020, July 15) Aljazeera News. https://www.aljazeera.com/news/2020/01/timeline-china-coronavirus-spread-20012 6061554884.html

[3] Aljazeera (2020, January 31) Aljazeera News. https://www.aljazeera.com/news/2020/01/declares-coronavirus-global-emergency-d eath-toll-rises-200130231243350.html

[4] Zhang, H. and Shaw, R. (2020) Identifying Research Trends and Gaps in the Context of COVID-19. International Journal of Environmental Research and Public Health, 17, 3370. https://doi.org/10.3390/ijerph17103370

[5] Zhong, B.-L., Luo, W., Li, H.-M., Zhang, Q.-Q., Liu, X.-G., Li, W.-T. and Li, Y. (2020) Knowledge, Attitudes, and Practices towards COVID-19 among Chinese Residents during the Rapid Rise Period of the COVID-19 Outbreak: A Quick Online Cross-Sectional Survey. International Journal of Biological Science, 16, 1745-1752. https://doi.org/10.7150/ijbs.45221

[6] WHO (2020) COVID-19 Dashboard. https://covid19.who.int/?gclid=CjwKCAjwjLD4BRAiEiwAg5NBFk8mNdeQfGyncP eTvxCo1hH2P7ZdsMP9YGIIPFOzkqVjfhpEw4-dyRoC3FAQAvD_BwE

[7] Institute of Epidemiology, Disease Control and Research (IEDCR) (2020, July 13). https://iedcr.gov.bd

[8] Qian, X., Ren, R., Wang, Y., Guo, Y., Fang, J., Wu, Z.-D., Liu, P.-L. and Han, T.-R. (2020) Fighting against the Common Enemy of COVID-19: A Practice of Building a Community with a Shared Future for Mankind. Infectious Diseases of Poverty, 9 , 34. https://doi.org/10.1186/s40249-020-00650-1

[9] Chen, N., Zhou, M., Dong, X., Qu, J., Gong, F., Han, Y., Qiu, Y., et al. (2020) Epidemiological and Clinical Characteristics of 99 Cases of 2019 Novel Coronavirus Pneumonia in Wuhan, China: A Descriptive Study. The Lancet, 395, 507-513. https://doi.org/10.1016/S0140-6736(20)30211-7

[10] Huang, L., Xu, F. and Liu, H. (2020) Emotional Responses and Coping Strategies of 
Nurses and Nursing College Students during COVID-19 Outbreak. https://doi.org/10.1101/2020.03.05.20031898

[11] Qualls, N., Levitt, A., Kanade, N., Wright-Jegede, N., Dopson, S., Matthew Biggerstaff, M., Carrie Reed, C. and Uzicanin, A. (2017) Community Mitigation Guidelines to Prevent Pandemic Influenza-United States. Morbidity and Mortality Weekly Report, 66, 1-34. https://doi.org/10.15585/mmwr.rr6601a1

[12] US Centers for Disease Control and Prevention (CDC) (2020). https://www.cdc.gov/nonpharmaceutical-interventions/index.html

[13] World Health Organization (WHO) (2020). https://www.who.int/health-topics/coronavirus\#tab=tab_1

[14] SEGCENCPCPMA, Special Expert Group for Control of the Epidemic of Novel Coronavirus Pneumonia of the Chinese Preventive Medicine Association (2020) An Update on the Epidemiological Characteristics of Novel Coronavirus Pneumonia (COVID-19). Chinese Journal of Epidemiology, 41, 139-144.

[15] Pan American Health Organization (PAHO) (2020). https://www.paho.org/disasters/index.php?option=com_docman\&view=download \&category_slug=tools\&alias=530-pandinflu-leadershipduring-tool-4\&Itemid=1179 \&lang=en

[16] Fong, M.W., Gao, H., Wong, J.Y., Xiao, J., Shiu, E., Ryu, S. and Cowling, B.J. (2020) Nonpharmaceutical Measures for Pandemic Influenza in Nonhealthcare SettingsSocial Distancing Measures. Emerging Infectious Diseases, 26, 976-984. https://doi.org/10.3201/eid2605.190995

[17] Markel, H., Lipman, H.B., Navarro, J.A., Sloan, A., Michalsen, J.R. and Stern, A.M. (2007) Nonpharmaceutical Interventions Implemented by US Cities during the 1918-1919 Influenza Pandemic. JAMA, 298, 644-654. https://doi.org/10.1001/jama.298.6.644

[18] Caley, P., Philp, D.J. and McCracken, K. (2008) Quantifying Social Distancing Arising from Pandemic Influenza. Journal of the Royal Society Interface, 5, 631-639. https://doi.org/10.1098/rsif.2007.1197

[19] Goh, K.T., Cutter, J., Heng, B.H., Ma, S., Koh, B.K.W., Kwok, C., Toh, C.-M. and Chew, S.K. (2006) Epidemiology and Control of SARS in Singapore. Annals of the Academy of Medicine of Singapore, 35, 301-316. https://pubmed.ncbi.nlm.nih.gov/16829997

[20] Wilder-Smith, A. and Freedman, D.O. (2020) Isolation, Quarantine, Social Distancing and Community Containment: Pivotal Role for Old-Style Public Health Measures in the Novel Coronavirus (2019-nCoV) Outbreak. Journal of Travel Medicine, 27, 1-4. https://doi.org/10.1093/jtm/taaa020

[21] Cetron, M. and Simone, P. (2004) Battling 21st-Century Scourges with a 14th-Century Toolbox. Emerging Infectious Diseases, 10, 2053-2054.

https://doi.org/10.3201/eid1011.040797_12

[22] CDC (2004) Public Health Guidance for Community-Level Preparedness and Response to Severe Acute Respiratory Syndrome (SARS). US Centers for Disease Control and Prevention (CDC), Atlanta.

https://www.cdc.gov/sars/guidance/d-quarantine/community.html

[23] CDC (2007) Interim Pre-Pandemic Planning Guidance: Community Strategy for Pandemic Influenza Mitigation in the United States: Early, Targeted, Layered Use of Nonpharmaceutical Interventions. US Centers for Disease Control and Prevention (CDC), Atlanta.

[24] Anwar, S., Nasrullah, M. and Hosen, M.J. (2020) COVID-19 and Bangladesh: Chal- 
lenges and How to Address Them. Frontiers in Public Health, 8, Article No. 154. https://doi.org/10.3389/fpubh.2020.00154

[25] Dhaka Tribune (2020, March 16).

https://www.dhakatribune.com/bangladesh/dhaka/2020/03/16/govt-directs-shutting -all-educational-institutions-mach-17-to-31

[26] Dhaka Tribune (2020, March 23).

https://www.dhakatribune.com/bangladesh/2020/03/23/govt-offices-to-remain-clos ed-till-april-4

[27] World Health Organization (WHO) (2020, June 4).

https://www.who.int/emergencies/diseases/novel-coronavirus-2019/advice-for-publ ic

[28] New Age (2020, March 25).

https://www.newagebd.net/article/103151/bangladesh-pm-urges-all-to-stay-at-hom e-to-fight-against-coronavirus

[29] Wang, G. (2020) Stay at Home to Stay Safe: Effectiveness of Stay-at-Home Orders in Containing the COVID-19 Pandemic. Social Science Research Network (SSRN).

https://doi.org/10.2139/ssrn.3581873

[30] Ferguson, N., Laydon, D., Nedjati Gilani, G., Imai, N., Ainslie, K., Baguelin, M., Bhatia, S., et al. (2020) Report 9: Impact of Non-Pharmaceutical Interventions (NPIs) to Reduce COVID19 Mortality and Healthcare Demand. Medical Research Council (MRC), The Royal Society, Imperial College London, London.

[31] World Health Organization (WHO) (2020). https://www.euro.who.int/en/health-topics/health-emergencies/coronavirus-covid19/technical-guidance/who-tool-for-behavioural-insights-on-covid-19/survey-tooland-guidance-behavioural-insights-on-covid-19,-17-april-2020 